\title{
Studi Kesiapan Konsep Personal Higiene pada Masyarakat Menuju Desa Wisata Edukasi Kulinologi
}

\author{
Muhammad Prasetya Kurniawan ${ }^{1}$, Novita Erma Kristanti ${ }^{1}$, Mohammad Wahyudin ${ }^{1}$, \\ Wildan Fajar Bachtiar², Annisa Dwi Astari ${ }^{1}$ \\ ${ }^{1}$ Fakultas Teknologi Pertanian,Universitas Gadjah Mada, Yogyakarta, Indonesia \\ ${ }^{2}$ Program Studi Diploma Agroindustri, Universitas Gadjah Mada, Yogyakarta, Indonesia \\ Email: kurniawan_prasetya@ugm.ac.id
}

Submisi 08 November 2017; Penerimaan 14 Februari 2019

\section{Kata kunci:diseminasi, praktik, pengetahuan, kesadaran, personal hygiene}

ABSTRAK Identifikasi kesiapan masyarakat menyongsong fungsi desa dari lumbung pangan rakyat menjadi wahana edukasi berketahanan pangan dilakukan untuk mengidentifikasi pemahaman dan kesadaran masyarakat mengenai higiene personal. Observasi, wawancara, dan penggunaan kuisioner digunakan untuk menilai 100 responden dari 8 pedukuhan di Desa Banyusoco, Playen, Gunungkidul. Tingkat pengetahuan, pemahaman, dan kesadaran mengenai higienitas diri ditinjau dari pelaksanaan sosialiasi, dampak dari kegiatan diseminasi dan pelatihan, frekuensi mencuci tangan sebelum menangani pangan, frekuensi mencuci tangan dengan sabun atau disinfektan setelah menggunakan toilet, di tempat makan, dan waktu selama minimal 20 detik penggunaan sabun. Analisis kesiapan juga ditinjau dari tingkat edukasi. Hasil identifikasi menunjukkan bahwa kebiasaan sehari-hari yang mempengaruhi kesadaran dibutuhkan. Namun demikian, penelitian dan diseminasi lebih lanjut diperlukan untuk menjelaskan perbedaan antara laporan perilaku, kemampuan, dan kesadaran.

\section{Keywords:}

dissemination, practice, knowledge, consciousness, personal hygiene
ABSTRACT The identification of the community's readiness to develop their capability from farming to culinary to support food security needs understanding and awareness about personal hygiene. Observations, interviews, and questionnaires were used to determine 100 respondents from 8 sub villages in Banyusoco, Playen, Gunungkidul. The level of knowledge, understanding, and awareness of self-hygiene is explored from the implementation of socialization, the impact of dissemination and training activities, the frequency of hand washing before handling food, the frequency of handwashing with soap or disinfectant after using the toilet, at the dining area, and time for at least 20 seconds use of soap. Readiness analysis is also reviewed from the level of education. The results of identification show that daily habits that affect consciousness are needed. However, further research and dissemination are needed to explain the differences between behavioral reports, abilities, and awareness.

\section{PENDAHULUAN}


Keamanan pangan merupakan salah satu perhatian utama dalam hal penyediaan sumber pangan dan peningkatan kualitas hidup manusia. Makanan merupakan kebutuhan mendasar bagi hidup manusia. Produk pangan siap mudah terkontaminasi dan mengakibatkan penyakit akibat (foodborne diseases) sehingga memerlukan penanganan aseptis untuk mencegahnya. BBPOM mengadakan Pemetaan Kasus Keracunan Pangan setiap periode untuk mendapatkan gambaran secara epidemiologis kasus keracunan dan kejadian luar biasa (KLB) pangan yang terjadi di Indonesia. Penyakit akibat pangan telah mengalami peningkatan jumlah dan luasan wilayah kejadian secara signifikan. Yunus dlkk (2015) memaparkan bahwa higiene dan sanitasi merupakan hal yang penting dalam menentukan kualitas pangan, dimana Escherichia coli digunakan sebagai salah satu indikator cemaran pangan yang memicu penyakit akibat makanan (food borne diseases). Menurut Tan et al., (2013), kurangnya kesadaran masyarakat terhadap program higiene pada diri dan lingkungan, kontaminasi makanan, kontaminasi silang, tata cara penanganan pangan khususnya faktor suhu yang tidak tepat selama penyimpanan dan persiapan makanan, dan sanitasi yang buruk merupakan salah satu alasan utama tingginya kasus keracunan pangan (Gambar 1).

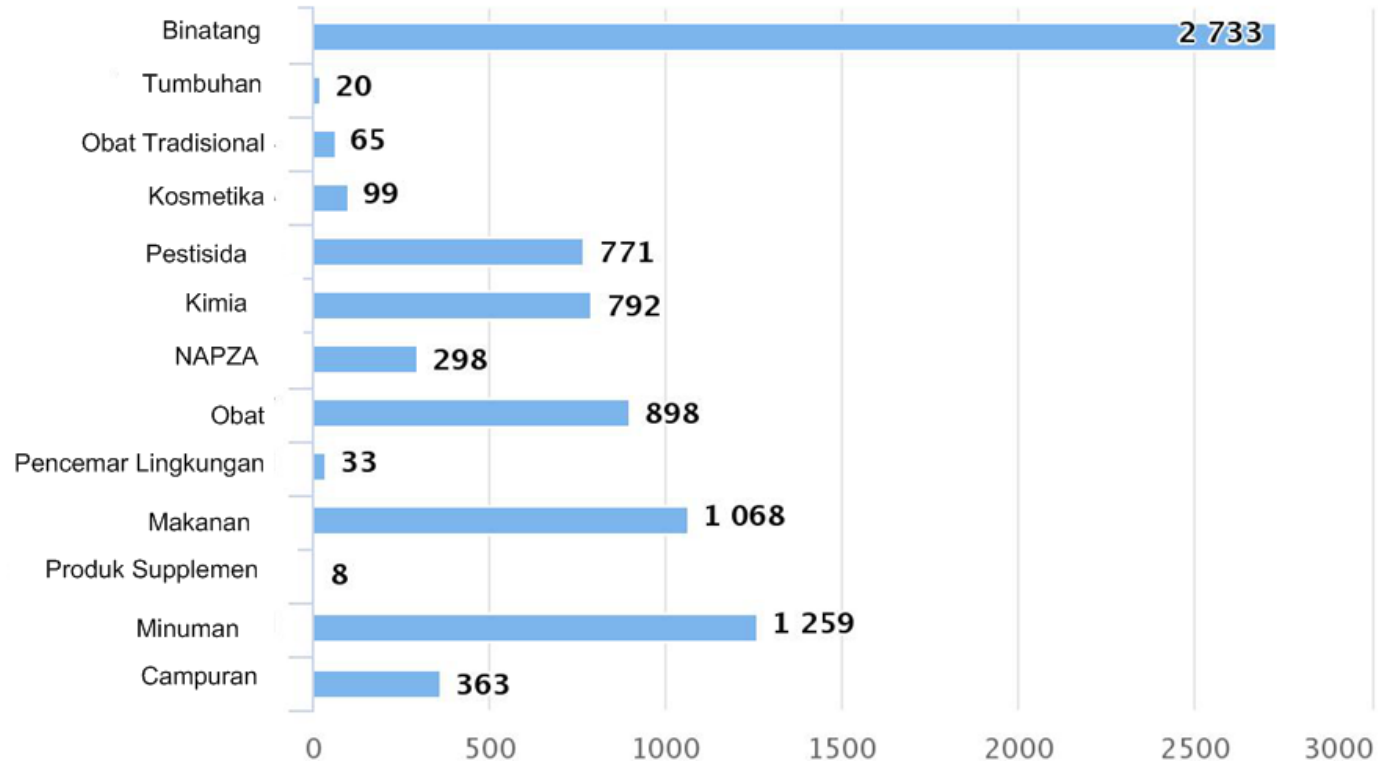

Sumber BPOM (2017).

Gambar 1. Kasus Keracunan Nasional Bardasarkan Kelompok Penyebab Tahun 2016

\section{TINJAUAN PUSTAKA}

Faktor risiko penyakit akibat pangan mengindikasikan timbulnya wabah penyakit berasal dari praktik penanganan pangan yang tidak tepat (Gambar 2). Sebagian besar korban penyakit akibat pangan disebabkan karena mengonsumsi makanan yang terkontaminasi yang disebabkan oleh beragam patogen yang berbeda. Kebiasaan dan kebersihan pribadi (personal hygiene) yang buruk sebagian besar menyebabkan penyakit, gangguan kesehatan, dan keracunan makanan (Fatmawati, 2013).Jianu dan Golet (2014) memaparkan bahwa kebersihan tangan dan peralatan makan memegang peranan penting dalam pengendalian penyebaran penyakit menular. Mencuci tangan dengan air bersih mengalir dan sabun atau desinfektan selama minimal 20 detik masih belum dilaksanakan secara benar oleh sebagian masyarakat yang akan menangani pangan atau setelah menggunakan toilet. Kualitas air dan 
selalu menjaga kebersihan tangan selama beraktiftas mampu mengurangi potensi penyakit akibat pangan (Johannessen dlkk., 2014).

Sebagai salah satu sasaran pengembangan Desa Banyusoco, Playen, Gunungkidul, peningkatan pemahaman, kemampuan, dan kesadaran masyarakat mengenai keamanan sangat penting untuk mendorong menciptakan lingkungan yang higienis. Banyak kasus penyakit akibat pangan yang terjadi diakibatkan karena susahnya merubah kebiasaan untuk hidup lebih bersih, kurangnya pemahaman mengenai personal hygiene, keterampilan dalam menerapkan kondisi aseptis, dan sinergi antara lembaga terkait dalam pelaksanaan program mengendalikan keamanan pangan (BPOM, 2016). Dengan demikian, berkomunikasi antara masyarakat, pemangku kebijakan, akademisi, dan industri makanan merupakan komponen menjadi semakin penting dalam sistem keamanan pangan untuk membangun masyarakat desa Banyusoco serta mengembangkan potensi kulinernya. Silva et al. (2014) memaparkan bahwa latar belakang, budaya, dan etika yang beragam mempengaruhi praktik dan perilaku keamanan pangan dalam suatu kawasan.

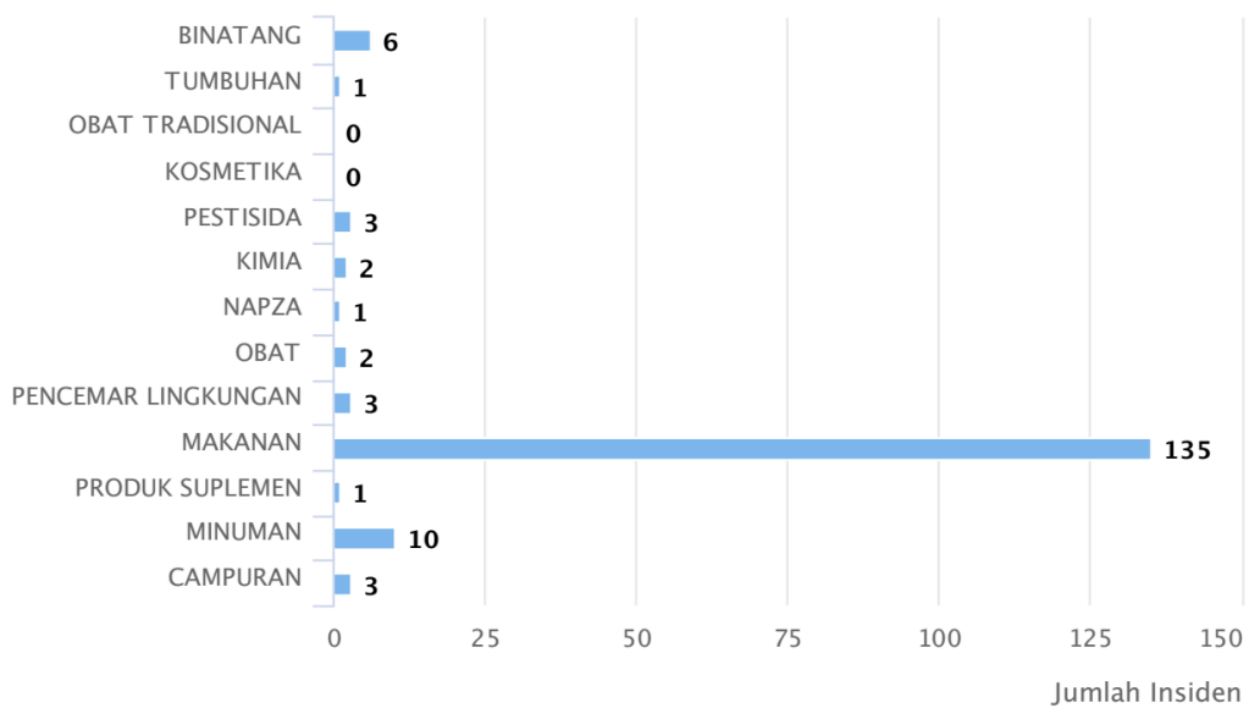

Sumber BPOM (2017).

Gambar 2. Insiden Keracunan Nasional Bardasarkan Kelompok Penyebab Tahun 2016

Pengembangan potensi Desa Banyusoco, Playen, Gunungkidul memerlukan penyediaan faktor pendukung yang bersinergi dengan kearifan lokal untuk peningkatan kemampuan desa, salah satunya bidang kuliner. Pengembangan bidang kuliner sangat erat dengan peningkatan sistem keamanan pangan yang wajib dibangun dari semua lini (PERMENKES No.1096, 2011). Kurangnya informasi tentang penyakit akibat pangan dan praktik kebersihan pribadi (personal hygiene), serta kurangnya informasi pendukung terkait dengan kesadaran dan kesenjangan dalam keselamatan saat mengonsumsi pangan harus diatasi secara menyeluruh.

Studi ini dilakukan pada bulan Juli sampai dengan Agustus 2017, yang melibatkan 100responden masyarakat Desa Banyusoco ( 8 pedukuhan), berusia 18 - 80 tahun, dibantu oleh mahasiswa peserta KKN PPM periode Juli - Agustus 2017. 


\section{METODE PENELITIAN}

Survei ke rumah tangga dan usaha pengolahan pangan, observasi kegiatan serta menilai tingkat pengetahuan, pemahaman, dan kesadaran mengenai higienitas diri ditinjau dari dampak dari kegiatan diseminasi dan pelatihan, frekuensi mencuci tangan sebelum menangani pangan, frekuensi mencuci tangan dengan sabun atau disinfektan setelah menggunakan toilet, di tempat makan, dan waktu selama minimal 20 detik penggunaan sabun dilakukan kepada masyarakat untuk meningkatkan kemampuan mereka (capacity building).

Jumlah responden ditentukan ketentuan sebagai berikut:

$\mathrm{n}=\frac{\mathrm{N}}{\mathrm{N}(\mathrm{d})^{2}+1}$, dengan

$\mathrm{n}=$ jumlah sampel yang dicari

$\mathrm{N}=$ jumlah populasi

$\mathrm{D}=$ nilai presisi, dalam studi ini dipilih $10 \%$

Dengan jumlah penduduk tahun 2016 sebanyak 6030 orang, maka jumlah responden 100 orang sudah memenuhi ketentuan. Analisis statistik dilakukan dengan menggunakan SPSS 22 IBM for windows dengan tingkat signifikansi statistik ditetapkan sebesar $10 \%$.

\section{HASIL DAN PEMBAHASAN}

\subsection{Informasi demografis responden}

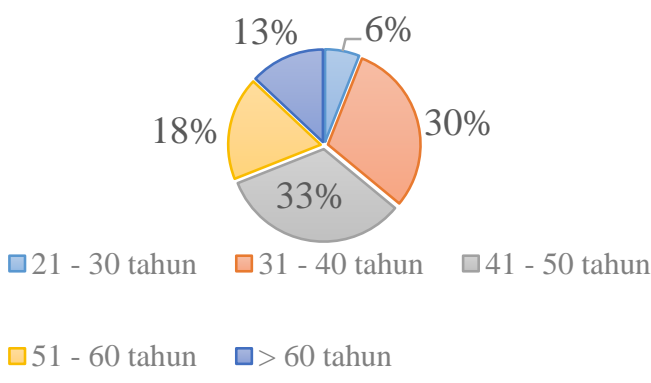

(a)

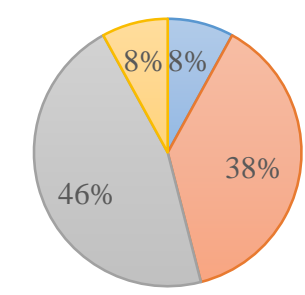

$\square \mathrm{SD} \square \mathrm{SMP} \square \mathrm{SMA} \square \mathrm{PT}$

(b)

Sumber: Data Primer (2017).

Gambar 3 (a) dan (b). Sebaran Usia dan Tingkat Pendidikan Responden

Responden yang digunakan berusia antara 20-60 tahun dengan tingkat pendidikan serata SD, SMP, SMA, dan Perguruan Tinggi (D1, D2, D3, dan S1). Sebagian besar masyarakat Desa Banyusoco, Playen, Gunungkidul bekerja di sektor agraris. Perkembangan di sektor industri sampai dengan tahun 2013 tumbuh sejalan meningkatnya kemampuan masyarakat memanfaatkan sumber daya disekitarnya, salah satunya dengan pengolahan hasil perikanan, pertanian dan perkebunan. Permasalahan utama yang dialami pelaku usaha mikro dan kecil di Desa Banyusoco adalah untuk pemasaran dan meraih pangsa pasar yang luas. Adanya beberapa kelompok industri seperti produk alat pertanian, kerajinan kulit, mebel, dan home industri apabila bersinergi dan lebih terkelola melalui BUMDES, diharapkan mampu menguatkan potensi Desa Banyusoco. 


\subsection{Tingkat kepentingan diseminasi dan pelatihan}

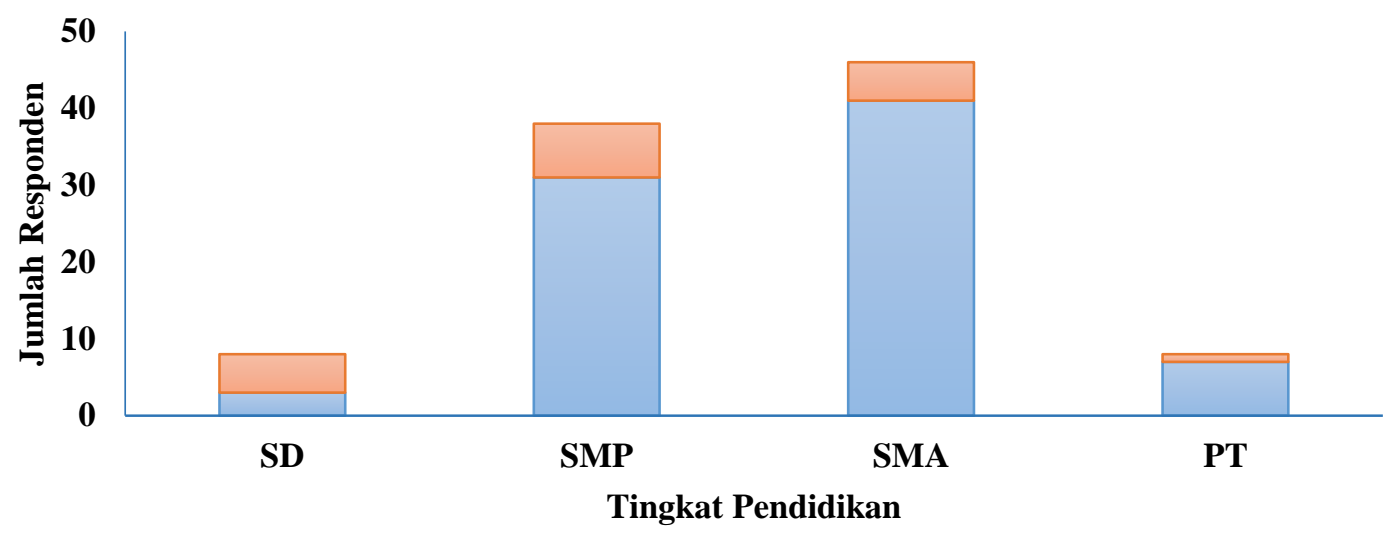

$\square$ Sangat bermanfaat (1) $\quad \square$ Cukup bermanfaat (2) $\quad \square$ Tidak bermanfaat (3)

Sumber: Data Primer (2017).

Gambar 5. Respon Tingkat Kepentingan Kegiatan Diseminasi dan Pelatihan

Gambar 5 menunjukkan hasil identifikasi yang berkaitan dengan kemanfaatan diseminasi dan praktik personal hygiene. Bentuk kemanfaatan sebagai umpan balik responden adalah menumbuhkan driving force perilaku hidup bersih dan sehat mulai dari diri sendiri, keluarga, dan masyarakat sekitar. Responden diarahkan menjadi agent of change menjadi lebih higienis dan mempraktikan mulai dari yang sederhana tentang kebersihan diri.

\subsection{Cuci Tangan Saat Menangani Produk Pangan}

Kebiasaan cuci tangan dengan air bersih dan sabun menjadi tolak ukur kinerja dalam menciptakan produk pangan yang aman. Tangan yang bersih akan memotivasi penjamah pangan untuk memerhatikan kebersihan perangkat pengolah pangan, lingkungan, serta proses yang dilalui hingga menjadi produk pangan. Kebiasaan mencuci tangan sebelum menjamah makanan, minuman dan peralatan harus ditumbuhkan dalam lingkup keluarga dan dilaksanakan secara disiplin. Hal tersebut berkaitan dengan membentuk karakter personal hygiene seperti selalu menyediakan lingkungan yang bersih setiap saat, diantaranya dengan memotong kuku agar tetap pendek, serta tidak menggunakan cat kuku.

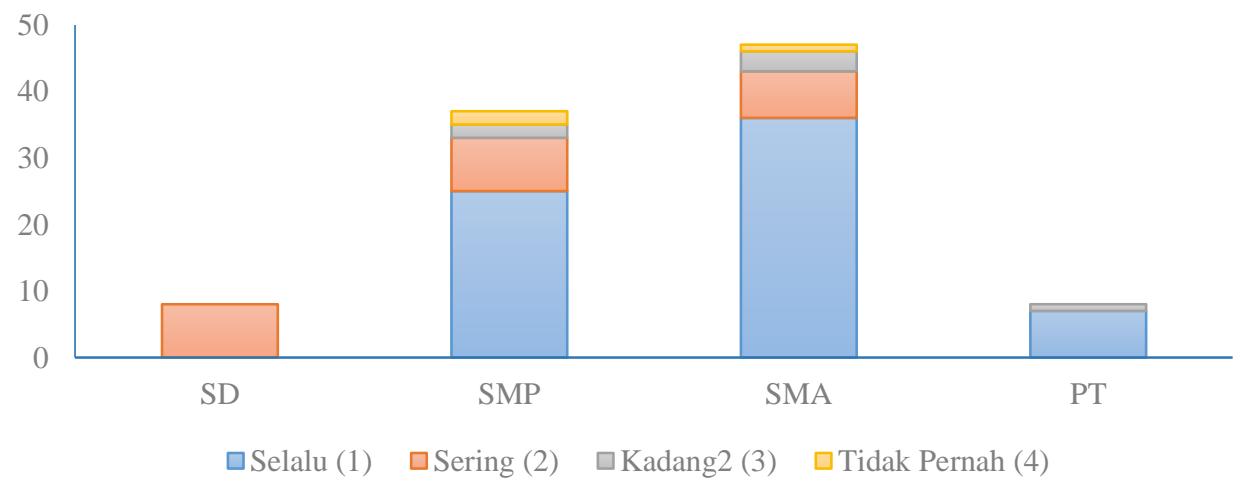

Sumber: Data Primer (2017).

Gambar 6. Sebaran Aktifitas Cuci Tangan Responden saat Menangani Produk Pangan 
Gambar 6 menunjukkan frekuensi cuci tangan menggunakan sabun dan air yang mengalir sebagai upaya mengantisipasi pencemaran pangan berkaitan dengan cuci tangan yang tidak sempurna. Menurut Rahmawati dan Triyana (2008), proses cuci tangan dilakukan untuk memutus jalur transmisi mikroorganisme dari tangan ke sumber lain serta mengurangi bakteri residen. Pseudomonas aeruginosa, Klebsiella pneumoniae, Serratia marcescens, Escherichia coli, dan Staphylococcus aureus dapat bertahan hidup sampai 90 menit jika inokulasikan secara buatan di atas jari-jari tangan. Cuci tangan dengan menggunakan sabun dan air, yang berfungsi sebagai bahan emulsifikasi untuk melarutkan kotoran, lemak, dan minyak pada tangan, akan menghilangkan bakteri transien yang bersifat patogen. Peningkatan friksi melalui penggosokan kedua tangan atau penggunaan sikat dengan sabun akan mengurangi jumlah bakteri transien dan residen dibandingkan dengan cuci tangan yang cepat atau tanpa penggosokan.

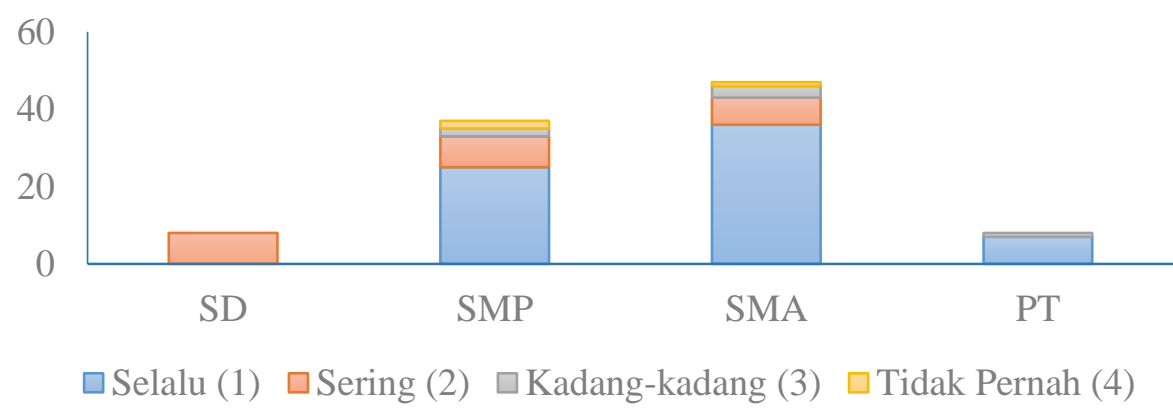

Sumber: Data Primer (2017).

Gambar 7. Sebaran Aktifitas Cuci Tangan setelah Menggunakan Toilet

Pada gambar 7, frekuensi kebiasaan cuci tangan setelah menggunakan kamar kecil ataupun (termasuk setelah kontak dengan cairan tubuh ketika batuk atau bersin) masih perlu ditingkatkan. Sebagian masyarakat masih mengabaikan potensi penularan penyakit setelah menggunakan jamban, toilet, dan area untuk kebersihan lainnya. Mengingat toilet dan cairan tubuh saat bersin atau batuk merupakan salah satu sumber kontaminan, proses pembersihan anggota tubuh yang mengalami kontak harus dilakukan pembersihan untuk meminimalkan dampak yang tidak diinginkan.

\subsection{Menyediakan Sabun/Desinfektan di Lokasi Mengolah Makanan dan Tempat Makan}

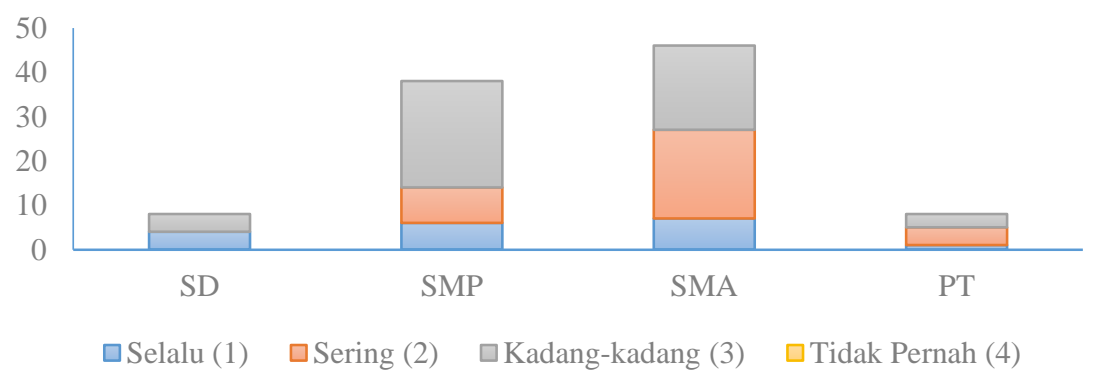

Sumber: Data Primer (2017)

Gambar 8. Sebaran Penyediaan sabun/desinfektan di Lokasi Mengolah Makanan dan Tempat Makan 
Gambar 8 menunjukkan perlu peningkatan kesadaran untuk selalu menyediakan sabun atau disinfektan didalam area dimana terdapat makanan, peralatan, barang sekali pakai dan benda-benda lain yang tidak boleh terkontaminasi. Alasan utama ketidaksediaan adalah penempatan di area kamar mandi sudah dirasakan cukup dan pengadaan sabun atau disinfektan perlu biaya di luar kebutuhan sehari-hari.

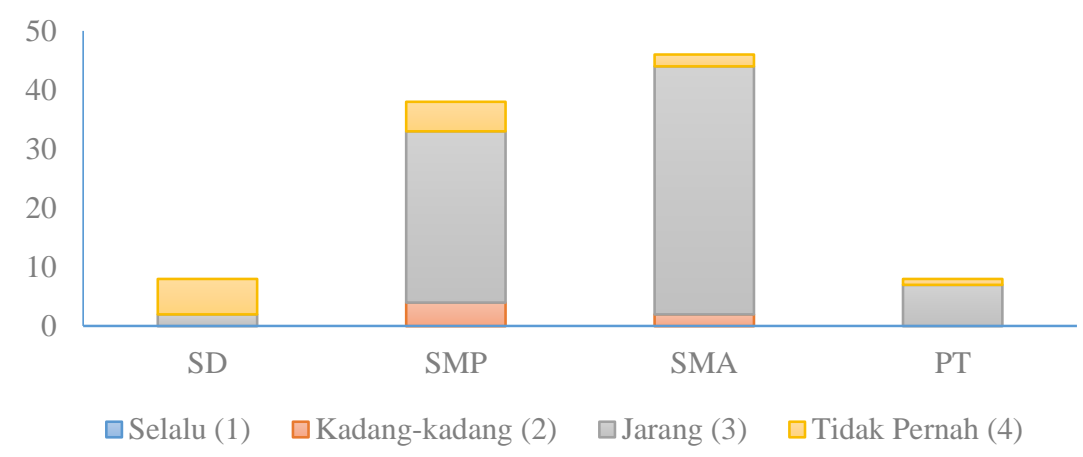

Sumber: Data Primer (2017)

Gambar 9. Menyediakan Sabun/desinfektan di Lokasi Mengolah Makanan dan Tempat Makan

Gambar 9 menunjukkan ketersediaan sabun atau desinfektan di area pengolahan pangan tidak dipengaruhi oleh tingkat pendidikan responden. Sebagian besar responden yang menyampaikan hal utama yang mendorong penyediaan sarana kebersihan adalah arahan dari PHBI dan peran akademisi dalam kegiatan pengabdian dan pengembangan kemampuan. Sebagian besar responden yang memiliki frekuensi cuuci tangan tinggi belum menggunakan air hangat saat mencuci tangan agar bakteri cepat mati. Waktu 20 detik merupakan batas minimal dari waktu ideal yaitu selama 40-60 detik masih belum dilaksanakan sebagian besar responden. Sebagian besar responden menyatakan apabila kondisi tangan sudah kesat dan terasa bersih menjadi acuan bahwa proses cuci tangan telah sempurna.

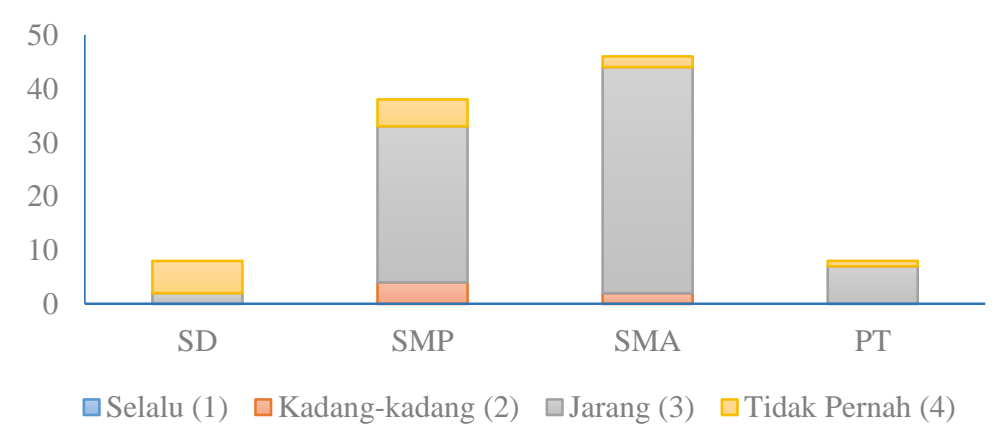

Sumber: Data Primer (2017)

Gambar 10. Menggunakan Sarung Tangan danCelemek saat Menangani Pangan

Penggunaan alat perlindungan diri saat mengolah pangan tidak dipengaruhi oleh tingkat pendidikan (Gambar 10). Sebagian besar pelaku usaha bidang pangan belum terbiasanya menggunakan sarung tangan sekali pakai (disposable) yang direkomendasikan digunakan untuk mencegah kontaminasi silang. Sebagian besar pelaku usaha menyatakan 
mencuci tangan dirasa telah mencukupi dan tidak terbiasa memakai sarung tangan. Dalam observasi dan wawancara ini, responden memahami dan berusaha untuk meningkatkan kinerja personal hygiene untuk tujuan pemenuhan tata laksana pengolahan pangan yang baik dan melindungi produk dari kontaminasi. Selama proses pengolahan terdapat beberapa persyaratan, antara lain meliputi :

1) Semua kegiatan pengolahan makanan harus dilakukan dengan cara terlindung dari kontak langsung dari tubuh, terutama bagian tubuh yang terluka.

2) Pada saat mengolah pangan, pakaian kerja minimal celemek (apron), masker (mounth and nose masker), dan penutup rambut (hair cover), khusus untuk penjamah makanan disediakan sarung tangan plastik yang sekali pakai (dispossable).

3) Perlindungan kontak langsung dengan makanan jadi menggunakan sarung tangan plastik, penjepit makanan, sendok, garpu dan sejenisnya.
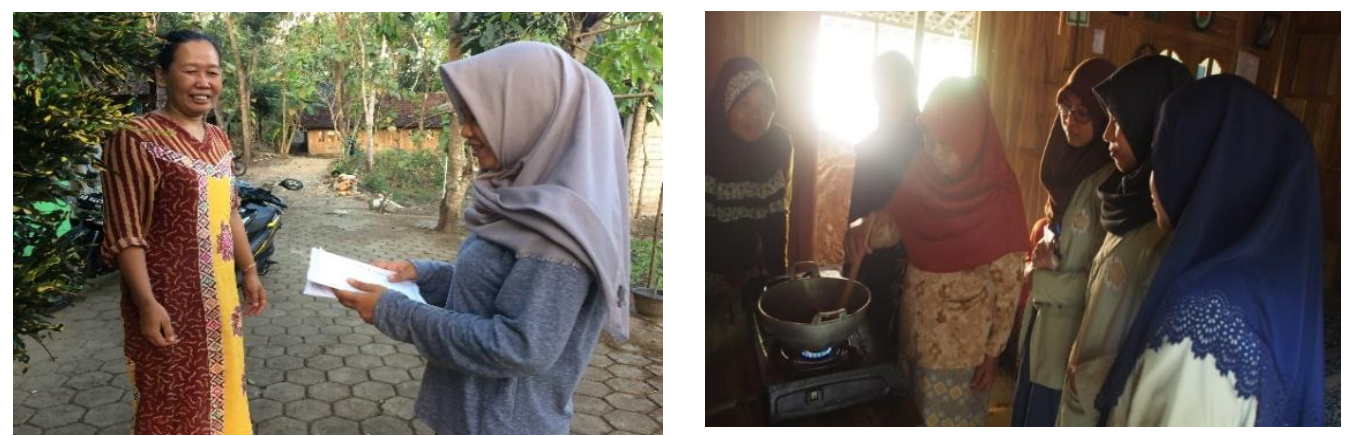

Sumber: Data Kegiatan KKN PPM Banyusoco (2017).

Gambar 12. Identifikasi, Observasi, dan Pengambilan Data ke Masyarakat Desa Banyusoco

Hasil diskusi dan diseminasi setelah rangkaian pelatihan menunjukkan bahwa rendahnya kinerja personal hygiene para responden antara lain disebabkan sebagai berikut:

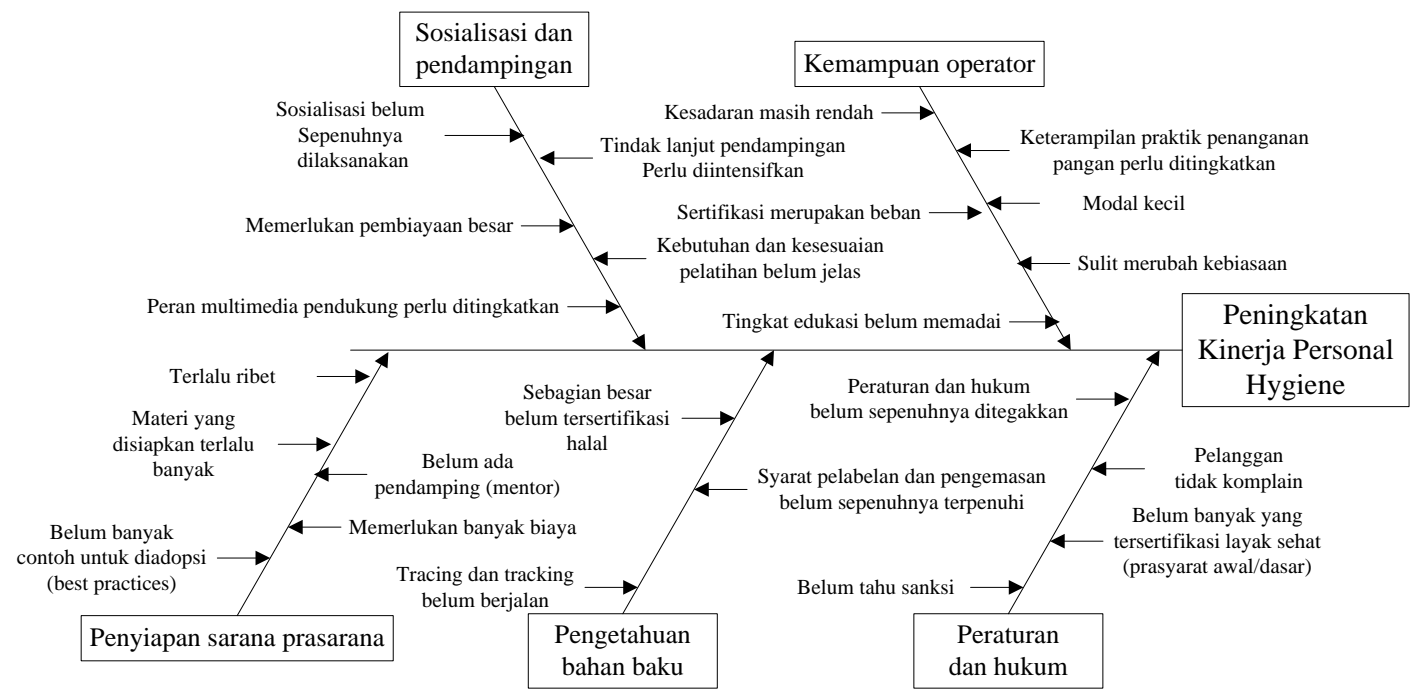

Sumber: Data Hasil Diskusi Kelompok Terarah (2017).

Gambar 12. Caused and Effect Diagram Implementasi Personal Hygiene dalam Rumah Tangga 
Persyaratan hygiene perilaku penjamah makanan, khususnya pada industri jasaboga telah diatur dan dijabarkan melalui Peraturan Menteri Kesehatan Republik Indonesia Nomor 1096/Menkes/Per/VI/2011dan Keputusan Menteri Kesehatan Republik Indonesia Nomor 1098/MENKES/SK/VII/2003tentang Persyaratan Hygiene Sanitasi untuk Rumah Makan dan Restoran. Namun demikian, informasi, sosialisasi, dan pendampingan belum sepenuhnya didapatkan oleh para calon pelaku industri jasaboga. Pemerintah, dalam hal ini kepada daerah bersama Departemen Kesehatan perlu secara berkelanjutan menjalin sinergi dengan perguruan tinggi dan masyarakat industri lain untuk menjamin praktek higiene oleh calon pelaku jasaboga.


Sumber: Data Kegiatan KKN PPM Banyusoco (2017).

Gambar 13. Diseminasi Penerapan Personal Hygiene dalam Rumah Tangga

Diseminasi hasil pembelajaran di perguruan tinggi, praktisi jasa boga, BPOM, dan dinas kesehatan mengenai sanitasi dan higiene pada industri pangan diharapkan mendorong kemampuan pelaku usaha pengolah untuk menerapkan dengan personal hygiene dengan baik.Proses pembelajaran yang terus menerus diharapkan meningkatkan kesiapan pelaku usaha pangan Desa Banyusoco meningkat ke level yang tinggi.Sinergi pihak terkait dan masyarakat diperlukan untuk mengadopsi konsep personal hygiene dan mengadaptasikan mulai dari lingkup keluarga guna peningkatan kualitas hidup masyarakat. Pembangunan kesadaran, pengetahuan dan keterampilan harus dimulai dari lingkup rumah tangga, karena seberapapun tingginya bantuan atau penyediaan fasilitas sanitasi serta personal hygiene tidak akan terlaksana tanpa terbangunnya kebiasaan kerja yang higienis harus dikembangkan untuk menghilangkan pencemaran pangan yang potensial.

\section{KESIMPULAN}

Tingkat pendidikan belum sepenuhnya menunjukkan penerapan personal hygiene masyarakat dan pelaku usaha bidang pangan di Desa Banyusoco. Kesiapan pengetahuan dan praktik kebersihan pribadi (personal hygiene) memerlukan keterlibatan pemerintah, pamong desa, akademisi, praktisi, dan masyarakat untuk adopsi pada tingkat keluarga.Sinergi untuk menuju desa wisata edukasi kulinologi dan berketahanan panganmemerlukan peningkatan kesadaran masyarakat tentang praktik keamanan dan kebersihan makanan pada usia muda dan pendampingan pada usia lanjut. Efek multimedia baik cetak maupun elektronik dapat memberikan pengetahuan di tingkat masyarakat, dan mendorong kesiapan dan perubahan perilaku dalam berinteraksi dengan produk pangan yang aman dalam rutinitas kehidupan sehari-hari. 


\section{Ucapan Terima Kasih}

Kegiatan dan studi ini didanai BPPTN BH Direktorat Pengabdian Kepada Masyarakat Universitas Gadjah Mada, dilaksanakan oleh Tim Pengabdian Kepada Masyarakat Departemen Teknologi Industri Pertanian FTP UGM, dan Tim KKN PPM GT-21, dan masyarakat Desa Banyusoco, Playen, Gunungkidul, Yogyakarta.

\section{Daftar Pustaka}

BPOM. (2016). Retrieved from http://ik.pom.go.id//v2016/

BPOM. (2017). Retrieved from http://www.pom.go.id/new/view/more/berita/11654/ Pemetaan-KasusKeracunan-dan-Surveilan-KLB-KP.html

Fatmawati S, Rosidi A, dan Handarsari E. 2013. Perilaku Higiene Pengolah Makanan Berdasarkan Pengetahuan Tentang Higiene Mengolah Makanan Dalam Penyelenggaraan Makanan di Pusat Pendidikan dan Latihan Olahraga Pelajar Jawa Tengah.Jurnal Pangan dan Gizi Vol. 04 No. 02.

Jianu C dan Golet I. 2014. Knowledge of food safety and hygiene and personal hygiene practices among meat handlers operating in western Romania. Food Control 42:214219.

Johannessen A., Rosemarin A., Thomalla F., Gerger Swartling A.G., Stenstrom T.A., dan Vulturius G. 2014. Strategies for building resilience to hazards in water,sanitation and hygiene (WASH) systems: The roleof public private partnerships. International Journal of Disaster Risk Reduction 10:102-115.

Keputusan Menteri Kesehatan Republik Indonesia Nomor 1098/MENKES/SK/VII/2003.

Peraturan Menteri Kesehatan Republik IndonesiaNomor 1096 / Menkes / PER / VI / 2011. TentangHigiene Sanitasi Jasaboga.

Rachmawati F.J. dan Triyana S.Y. 2008. Perbandingan Angka Kuman Pada Cuci Tangan Dengan BeberapaBahan Sebagai Standarisasi Kerja di LaboratoriumMikrobiologi Fakultas Kedokteran Universitas Islam Indonesia. Jurnal Penelitian \& Pengabdian dppm.uii.ac.id. Volume 5:Nomor 1.

Silva SA, Cardoso RSV, Góes JAW, Santos JN, Ramos FP, Jesus RB, Vale RS, Silva PST. 2014. Street food on the coast of Salvador, Bahia, Brazil: A study from the socioeconomic and food safety perspectives. Food Control 40 p.78-84.

Tan, S. L., Cheng, P. L., Soon, H. K., Ghazali, H. and Mahyudin, N. A. 2013. A qualitative study on personal hygiene knowledge and practices among foodhandlers at selected primary schools in Klang valley area, Selangor, Malaysia. International Food Research Journal 20(1): 71-76.

Yunus, S. P., Umboh, J. M. L., \& Pinontoan, M. 2015. Hubungan Personal Higiene dan Fasilitas Sanitasi dengan Kontaminasi Escherichia Coli Pada Makanan di Rumah Makan Padang Kota Manado Dan Kota Bitung dalam Jurnal Ilmu Kesehatan Masyaraka tUmum, Vol. 5, No. 2: 210-220. 